\title{
,anu \\ Optimization of Permanent Magnet Parameters in Axial Flux Rotary Converter for HEV Drive
}

\author{
Ales Havel *(i), Martin Sobek $(\mathbb{D}$, Libor Stepanec $(\mathbb{D}$ and Jan Strossa $(\mathbb{1}$ \\ Department of Electronics, VSB-Technical University of Ostrava, 70800 Ostrava-Poruba, Czech Republic; \\ martin.sobek@vsb.cz (M.S.); libor.stepanec@vsb.cz (L.S.); jan.strossa@vsb.cz (J.S.) \\ * Correspondence: ales.havel@vsb.cz
}

check for updates

Citation: Havel, A.; Sobek, M.; Stepanec, L.; Strossa, J. Optimization of Permanent Magnet Parameters in Axial Flux Rotary Converter for HEV Drive. Energies 2022, 15, 724. https:// doi.org/10.3390/en15030724

Academic Editor:

Frantisek Durovsky

Received: 20 December 2021

Accepted: 13 January 2022

Published: 19 January 2022

Publisher's Note: MDPI stays neutral with regard to jurisdictional claims in published maps and institutional affiliations.

Copyright: (C) 2022 by the authors. Licensee MDPI, Basel, Switzerland. This article is an open access article distributed under the terms and conditions of the Creative Commons Attribution (CC BY) license (https:// creativecommons.org/licenses/by/ $4.0 /)$.

\begin{abstract}
This paper focuses on the development and optimization of a special hybrid electric vehicle arrangement known as a four-quadrant rotary converter. The introduction summarizes the main advantages and disadvantages of existing topologies in radial and axial flux arrangements. Based on previous experience, we developed a novel axial flux arrangement that eliminates the problems and disadvantages associated with existing radial flux solutions. In addition, this paper evaluates and subsequently describes the optimization of permanent magnet parameters in an axial flux rotary converter unit. A number of 3D finite element method optimizations were performed to find the optimal mass distribution of permanent magnets on the frontal area of the outer rotor in the axial flux rotary converter unit. The optimization involved the permanent magnets' material, shape, and thickness in order to achieve maximal efficiency of the entire unit while leaving its nominal output power and speed unaffected. The results show an increase in the overall theoretical efficiency of the outer rotor unit from $90.2 \%$ to $94.4 \%$ following the optimization.
\end{abstract}

Keywords: axial flux; efficiency; finite element method; hybrid electric vehicle; permanent magnet

\section{Introduction}

The upper efficiency limit of an internal combustion engine (ICE) can be derived from the Carnot cycle. The efficiency of ICEs used in conventional vehicles does not usually exceed $40 \%$ [1]. However, this efficiency can only be achieved by an ICE in a relatively narrow area of mechanical conditions. Significant energy savings can be achieved with advanced configurations of hybrid electric vehicles (HEVs), where full speed and torque control is possible [2]. In other words, for an ICE to reach maximal efficiency during active operations and in all possible driving situations, full control of its torque and speed independent of each other is necessary [3,4].

This requirement is met by series hybrid arrangements, however, only at the cost of total mechanical energy being transformed to electricity and back, with power losses during each conversion. Moreover, an electric motor has to be oversized to match the maximal power of an ICE [5,6]. On the other hand, parallel hybrid arrangements utilize low-powered electric motors that are mechanically coupled to the gearbox; however, this only allows full control of the torque produced by an ICE, but not the speed [5,6].

Many of the HEV arrangements used today are based on the series-parallel hybrid topologies, which combine the advantages of both arrangements, such as full torque and speed control in the optimal working area of the ICE, as well as minimization of conversion losses between electrical machines. Among the main disadvantages of the series-parallel $\mathrm{HEV}$ topologies are the more complex structural arrangements and the higher demands on the energy flow control [5,6]. Several different topologies in both radial and axial arrangements will be considered in greater detail.

The four-quadrant transducer system in the radial arrangement and the continuously variable electromagnetic transmission in the axial arrangement are among the best-known 
solutions for series-parallel HEV conceptions [6,7]. The innovative concept presented in $[6,7]$ lies in the synthesis of two electrical machines (the electric motor and generator) into one double-rotor electrical machine with two air gaps. The outer rotor carries the permanent magnets (PMs) on both sides in order to interact with the rotating magnetic field of the stator winding and with the winding of the inner rotor, thereby continuously transmitting speed and torque (i.e., power) to the output shaft. The inner rotor is mechanically coupled with the ICE through the clutch, while the power flow is then completed through the slip rings and the indirect frequency converter, back to the stator [6,7]. Both electric submachines consisting of inner rotor and outer rotor (first submachine) and outer rotor and stator (second submachine) can operate here in the motor and generator mode. This concept can replace both the clutch and the gearbox in an HEV [6,7]. The main disadvantages of solutions $[6,7]$ lie in the relatively high mechanical stress placed on the outer rotor structure, the considerable thermal stress placed on the winding and insulation of the inner rotor, problematic cooling, and the need for frequent maintenance of the slip rings. These and similar technical issues, along with the detection of stator turn short-circuits, are discussed in $[8,9]$.

\section{Axial Flux Rotary Converter}

After carefully analyzing the disadvantages of the aforementioned arrangements, we developed a novel and modified arrangement. This solution is represented in Figure 1 as the axial flux rotary converter (AFRC) unit.

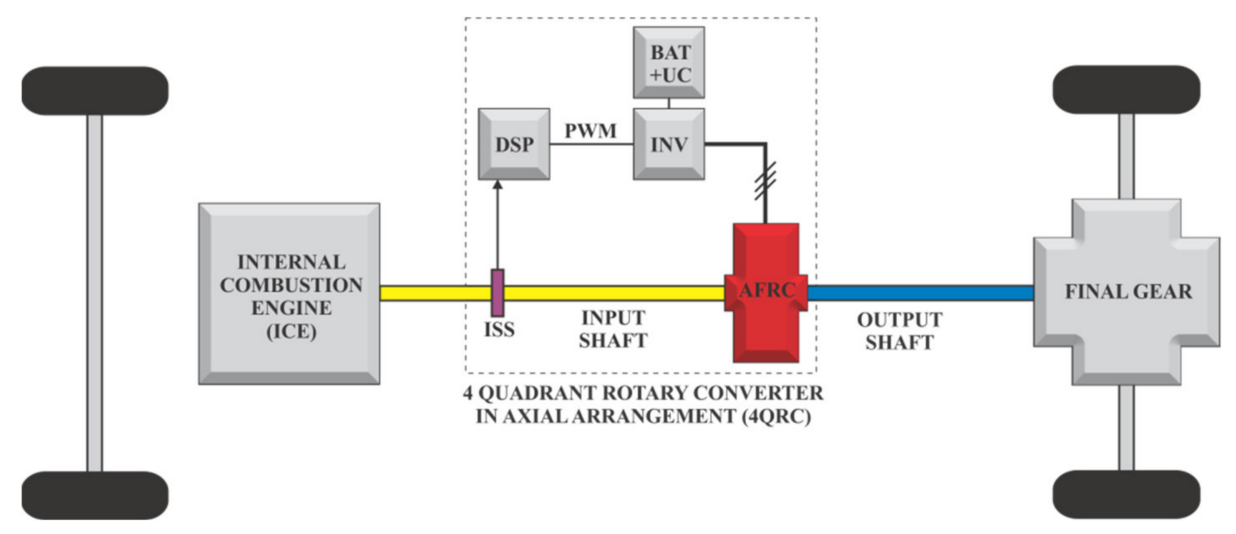

Figure 1. Integration of the axial flux rotary converter into the HEV drive unit. Reprinted from ref. [10].

The winding of the axial stator is powered by a three-phase voltage inverter (INV) from the DC power source, which can be built as a combined Li-ion battery (BAT) and ultracapacitor (UC) power source system.

The advantage of this hybrid supply lies in the fast energy intake and outtake of the ultracapacitors combined with the long-term storage ability of the battery. Proper interconnection of these two storage technologies has a crucial impact on the efficiency of the regenerative braking and the dynamic properties of the vehicle drive unit. Other benefits of using ultracapacitors can be found in the wider range of operating temperatures and in the significantly faster charging times in comparison to common Li-ion battery units $[11,12]$.

The control of the system is provided by a digital signal processor (DSP), with an implemented direct torque control (DTC) algorithm providing sufficient computational power and dynamics for the drive system [13-15]. The speed of the ICE is measured by an incremental speed sensor (ISS) that sits directly on the input shaft. The ISS provides the speed loop feedback to the DSP.

The main purpose of the AFRC unit is to allow the ICE to work in the maximal efficiency area of the entire torque-speed diagram in the final gear, thereby minimizing 
fuel consumption and reducing harmful emissions produced. The AFRC unit consists of a double rotor permanent magnet machine, attached to the input shaft end of the induction machine, which is then mounted on the output shaft. The chosen double rotor layout allows changes in both the torque and speed between the two shafts, thereby regulating the amount of power transmitted from the input shaft to the final gear. The power difference between the input and output shaft can be supplied by or drawn through the stator winding, which means that only a part of the total energy necessary for vehicle propulsion passes through the electromagnetic transmission. The surplus mechanical energy from the ICE or from the braking energy of the vehicle can be transformed through electromagnetic couplings between the outer rotor and the stator and then stored in the batteries or ultracapacitors.

The constructional simplicity of the AFRC unit is characterized by a disc arrangement, with two axial air gaps that run alongside the inner rotor. In turn, the inner rotor is equipped with double-sided squirrel cages. Both cages can simultaneously interact with the electromagnetic fields produced by the permanent magnets affixed to the outer rotor disc and/or by the three-phase winding from the stator disc. Thus, there are two different magnetic flux loops in the AFRC unit. The first loop is located on the side of the input shaft, where magnetic flux is produced by permanent magnets which are affixed to the outer rotor. The loop continues through air gap $\delta_{1}$ (Figure 2), passing to the adjacent squirrel cage of the inner rotor, before looping back along the same path. The second magnetic flux loop occurs on the side of the output shaft and is produced in the stator's three-phase winding. This loop continues through air gap $\delta_{2}$ (Figure 2), passing to the adjacent squirrel cage of the inner rotor and then loops back the same way, as seen in Figure 2.

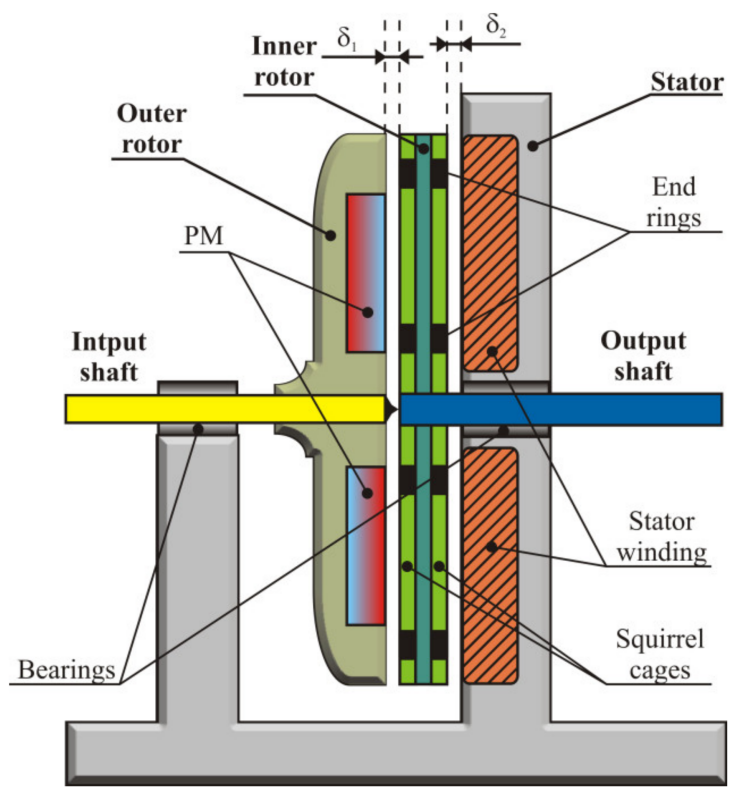

Figure 2. The internal structure of the AFRC unit. Reprinted from ref. [10].

It has been proven that the width of the air gap has a significant influence on the output characteristics and efficiency of axial-flux machines, especially on the ratio between stator copper losses and rotor core losses [16-21].

The AFRC unit can be operated in all four quadrants of the torque-speed diagram with respect to the optimal operation point of the internal combustion engine. There are five possible operation modes of the unit, as outlined below.

\subsection{Increasing Both Speed and Torque}

The required torque and speed at the final gear are greater than the torque and speed produced by the ICE. This mode is used when the HEV accelerates from a higher speed 
than that of the input shaft. The stator winding is supplied from the battery unit through the voltage inverter and the battery is discharged.

\subsection{Decreasing Speed and Increasing Torque}

The output shaft rotates at a lower speed than the input shaft and the required torque at the final gear is higher than the ICE's torque. This mode is used when the HEV is started from a standstill, is traveling loaded at low speeds, or generally when the ICE's optimal operation point is at a higher speed than that required of the final gear. Depending on the input to output power ratio, the battery unit can be charged or discharged in this mode.

\subsection{Decreasing Both Speed and Torque}

The ICE operates at a higher speed and torque than is required at the final gear. The induction machine operates in generator mode and charges the battery unit via the voltage inverter. Only part of the ICE's power is used for vehicle propulsion, with the remaining power being delivered to the battery unit. This mode is used in regenerative braking.

\subsection{Increasing Speed and Decreasing Torque}

The output shaft rotates at a higher speed than the input shaft and the torque required at the final gear is lower than the ICE's torque. This mode is generally used when the ICE's optimal operation point is at a lower speed than the speed required of the final gear. Depending on the input to output power ratio, the battery unit can be charged or discharged in this mode.

\subsection{Purely Mechanical or Electrical Mode}

The width adjustment of air gap $\delta_{1}$ enables the AFRC unit to operate in a purely mechanical or electrical mode. In the mechanical mode, only the ICE is used for vehicle propulsion, while the stator of the induction machine is not supplied. In electrical mode, the ICE's shaft is disconnected and Li-ion batteries and ultracapacitors alone are used for vehicle propulsion.

\section{Estimation of Permanent Magnet Parameters}

The results from the axial flux permanent magnet machine design were used as input parameters for a subsequent optimization analysis using the 3D finite element method (FEM). The main dimensions of the outer rotor were chosen to equal the dimensions of the inner rotor (rotor thickness $\left(h_{r}\right)$ and inner and outer diameters $\left(D_{I N}\right.$ and DOUT, respectively)). Commonly used $\mathrm{NdFeB}$ permanent magnets XG160/120 with parameters $B_{r}=880 \mathrm{mT}, H_{c}=640 \mathrm{kA} \cdot \mathrm{m}^{-1},(B H)_{\max }=150-184 \mathrm{~kJ} \cdot \mathrm{m}^{3}, T_{c}=700{ }^{\circ} \mathrm{C}, \rho=8.0-8.3 \mathrm{~g} \cdot \mathrm{cm}^{-3}$, and $\mu_{r}=1.05-1.1$ were preselected according to [16]. Air gap flux density was calculated using Equation (1), where the coefficient $k_{\delta}$ refers to the attenuation factor of magnetic flux density in the air gap [22].

$$
B_{\delta}=\frac{B_{r}}{k_{\delta}}
$$

The overload factor was estimated using Equation (2), where $P_{\max } / P_{2}$ is the ratio between the maximal estimated output power and the nominal output power of the AFRC unit.

$$
k_{o c f}=\frac{P_{\max }}{P_{2}}
$$

Equation (3) shows the calculation of the utilization factor, where $k_{f}$ is the PM's shape factor. The ratio of induced voltage to nominal voltage is represented by the coefficient $k_{e}$, whereas the PM's utilization coefficient $\xi$ was selected in accordance with [20].

$$
c_{v}=\frac{2 k_{o c f} k_{f}\left(1+k_{e}\right)}{\pi^{2} \xi}
$$


The total volume of the PMs was calculated using Equation (4), where $f_{n}$ is the supply frequency.

$$
V_{m}=\frac{c_{v} P_{2}}{f_{n} B_{r} H_{c}}
$$

The volume of one magnet was then calculated using Equation (5), where $2 p$ is the number of pole pairs.

$$
V_{1 m}=\frac{V_{m}}{2 p}
$$

The active surface area of the PMs was then calculated using Equation (6), where $k_{m}$ is the ratio of the active surface area of the PMs to the frontal area of the outer rotor disc and $S_{R}$ is the frontal area of the outer rotor disc.

$$
S_{m}=k_{m} S_{R}=k_{m} \cdot \frac{\pi}{4}\left(D_{\text {OUT }}^{2}-D_{I N}^{2}\right)
$$

The thickness of the PMs was calculated using Equation (7), and their weight, by using Equation (8).

$$
\begin{gathered}
h_{m}=\frac{V_{m}}{S_{m}} \\
m_{m}=\rho_{m} V_{m}
\end{gathered}
$$

Iron core losses were defined by Equation (9), where $\Delta p_{1.0}$ are specific losses of used steel and $\beta$ is the exponent dependent on its type. The coefficients $k_{d j}$ and $k_{d z}$ are the influence of uneven magnetic flux distribution in particular parts of the magnetic circuit and the influence of production technology, respectively. $B_{j 1}$ and $B_{z 1}$ are magnetic flux densities in the stator yoke and stator teeth, respectively; and finally, $m_{j 1}$ and $m_{z 1}$ are the weights of the stator yoke and the stator teeth, respectively.

$$
\Delta P_{F e}=\Delta p_{1.0}\left(\frac{f_{n}}{50}\right)^{\beta}\left(k_{d j} B_{j 1}^{2} m_{j 1}+k_{d z} B_{z 1}^{2} m_{z 1}\right)
$$

Mechanical losses were calculated using Equation (10), where $n_{S}$ is the synchronous speed of the rotor.

$$
\Delta P_{\text {mech }}=1.3\left(1-D_{\text {OUT }}\right) D_{\text {OUT }}^{4}\left(\frac{n_{s}}{10}\right)^{2}
$$

Additional losses were estimated using Equation (11). These losses arise due to stray fluxes and magnetic flux density pulsations in the air gap. The standard IEC60034-2 defines these losses as $0.5 \%$ of the nominal output power.

$$
\Delta P_{d}=0.005 \cdot P_{2}
$$

Stator winding copper losses were calculated using Equation (12), where $m$ indicates the number of phases, $R_{1}$ is the resistance of one phase of the stator winding, and $I_{n}$ is the nominal stator current.

$$
\Delta P_{j 1}=m R_{1} I_{n}^{2}
$$

The overall efficiency of the AFRC unit was calculated using Equation (13).

$$
\eta=\frac{P_{2}}{P_{2}+\Delta P_{F e}+\Delta P_{m e c h}+\Delta P_{d}+\Delta P_{j 1}}
$$

\section{Optimization of Machine Parameters Using 3D FEM Analysis}

We performed 3D FEM optimization analyses in the RMxprt/Maxwell environment. The optimization process focused mainly on material properties, volume, active area, shape, and thickness of the permanent magnets on the outer rotor, the shape and tilt of the inner rotor slots, and the shape of the stator slots, together with the stator winding parameters. 
The goal of the PM's shape optimization analysis was to find the optimal mass distribution of PMs on the frontal area of the outer rotor. The analysis is depicted on the left side in Figure 3 and was solved using a tri-variable solution (width, thickness, and active surface area) through a parametric sweep analysis with a subsequent quasi-Newtonian optimization method, while the key components of total losses, such as stator winding copper losses and iron core losses, were closely monitored in order to find the minimal sum of these functions.
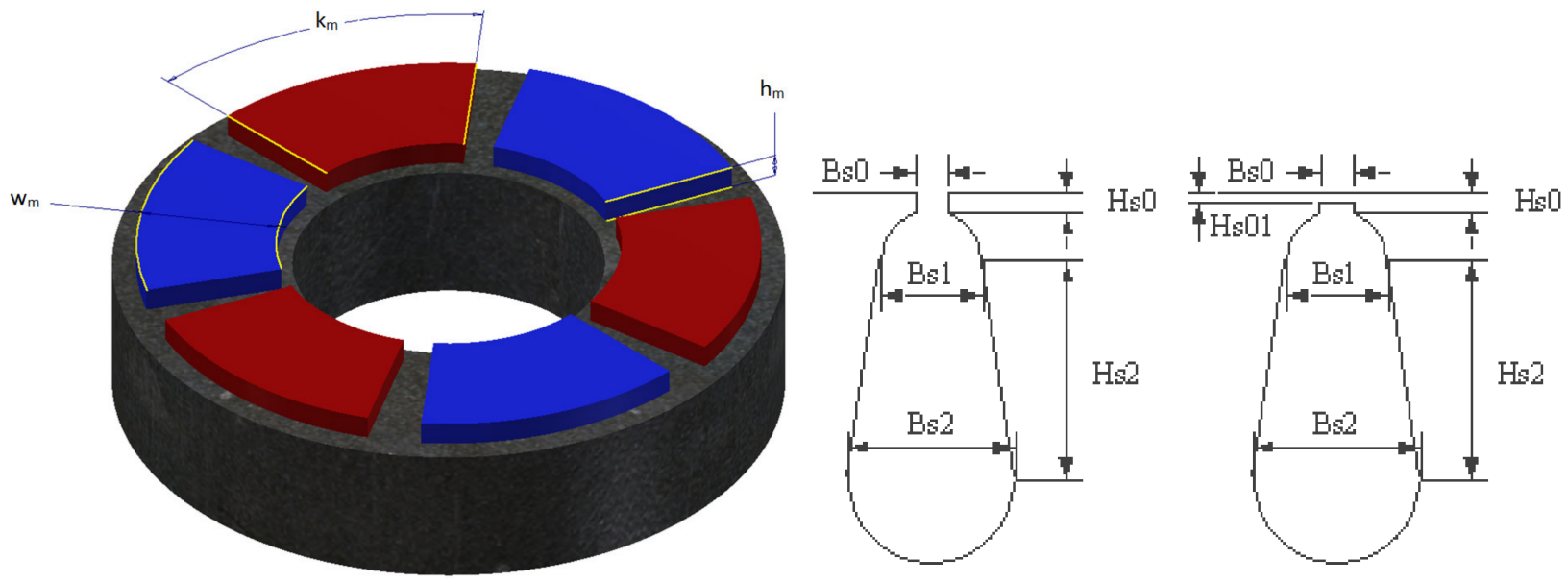

Figure 3. Finding the optimal width $\left(w_{m}\right)$, active surface area $\left(k_{m}\right)$, and thickness $\left(h_{m}\right)$ of permanent magnets on the outer rotor (left); finding the optimal dimensions of stator slots (center), and the optimal dimensions of the inner rotor closed slots (right).

The PM optimization analysis presented in this paper proves the optimal width of permanent magnets located between the outer and inner rotor radius. One of the $3 \mathrm{D}$ plots obtained during the optimization process shows the efficiency matrix for constant-width PMs (Figure 4).

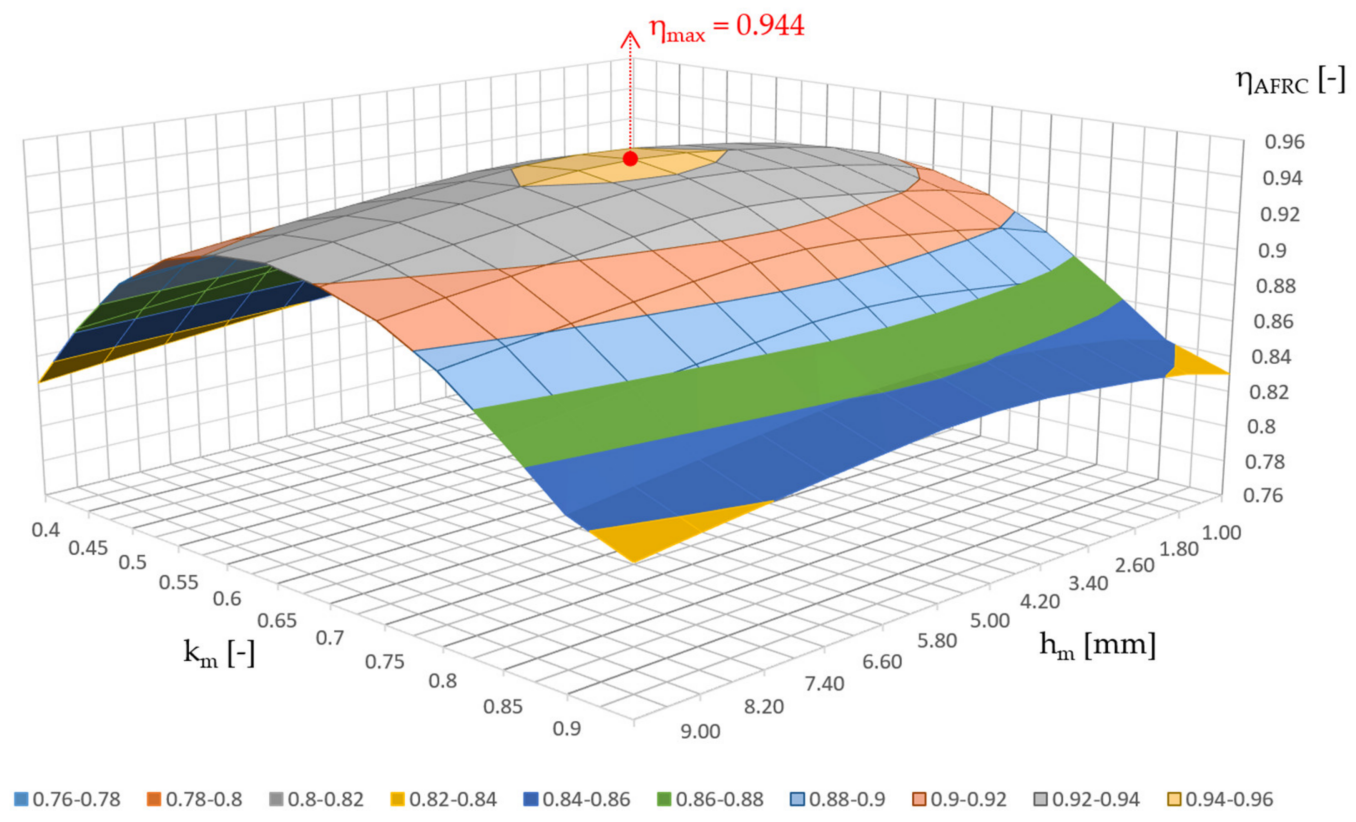

Figure 4. Overall efficiency $\eta$ of the optimized AFRC unit evaluated in a 3D plot as a function of the active surface area represented by parameter $k_{m}$ and thickness $h_{m}$ for constant-width $w_{m}$ permanent magnets. 
The optimal efficiency level achieved was relatively narrow and decreased sharply when the parameters were changed. For example, the air gap flux density dropped rapidly when the magnet thickness $\left(h_{m}\right)$ was reduced. Therefore, the amount of power transferred through the air gap was also reduced $[23,24]$.

Based on the data presented in Table 1, we decided to change the type of PMs to XG196/96 PMs, especially due to the optimal shape of their B/H curve, the resulting value of the magnetic flux density in the air gap, the relatively small volume required, and the highest overall efficiency of the AFRC unit compared to other types of permanent magnets tested during the optimization process.

Table 1. Characteristics of the AFRC unit using different types of permanent magnets.

\begin{tabular}{cccccccccc}
\hline $\begin{array}{c}\text { Magnet } \\
\text { Type }\end{array}$ & FLN & FLN & FLN & LN & LN & LN & XG & $\begin{array}{c}\text { XG } \\
\mathbf{1 6 0 / 1 2 0}\end{array}$ & $\begin{array}{c}\text { XG } \\
\mathbf{1 9 6 / 9 6}\end{array}$ \\
\hline$B_{r}(\mathrm{~T})$ & $\mathbf{8}$ & $\mathbf{G 2 8}$ & GT31 & $\mathbf{1 0}$ & $\mathbf{G 5 2}$ & $\mathbf{G T 7 2}$ & $\mathbf{1 1 2 / 9 6}$ & 0.96 \\
$H_{c}\left(\mathrm{kAm}^{-1}\right)$ & -40 & 1.05 & 0.76 & 0.60 & 1.30 & 1.05 & 0.73 & 0.88 & 0.96 \\
$B_{\delta}(\mathrm{T})$ & 0.25 & -46 & -107 & -40 & -56 & -112 & -520 & -640 & -690 \\
$\eta(\%)$ & 87.6 & 91.6 & 91.4 & 88.4 & 92.7 & 91.2 & 90.7 & 9.71 & 0.76 \\
\hline
\end{tabular}

A summary of the electromechanical parameters of the AFRC unit after conducting the aforementioned optimization is shown in Table 2; the optimized parameters of the machine are compared with the original parameters obtained in Section 3.

Table 2. Parameters of the AFRC Unit after permanent magnet optimization.

\begin{tabular}{ccccc}
\hline Optimized Parameter & Value/Unit & Originally & Optimized & Change \\
\hline Type of PMs & $(-)$ & XG160/120 & XG196/96 & Yes \\
Volume of PMs & $V_{m}\left(\mathrm{~cm}^{3}\right)$ & 36 & 39.5 & $-9.7 \%$ \\
Width of PMs & $w_{m}(\mathrm{~mm})$ & 37.5 & 0.65 & $-4 \%$ \\
Active area ratio & $k_{m}(-)$ & 0.75 & 78.5 & $-13.3 \%$ \\
Total area of PMs & $S_{m}\left(\mathrm{~cm}^{2}\right)$ & 91.3 & 5 & $-14.0 \%$ \\
Thickness of PMs & $h_{m}(\mathrm{~mm})$ & 4 & 0.31 & $+25 \%$ \\
Weight of PMs & $m_{m}(\mathrm{~kg})$ & 0.28 & 0.76 & $+10.7 \%$ \\
Air gap flux density & $B_{\delta 1}(\mathrm{~T})$ & 0.87 & 5.70 & $-12.6 \%$ \\
Nominal stator current & $I_{n}(\mathrm{~A})$ & 6.02 & 0.43 & $-5.3 \%$ \\
Stator winding resistance & $R_{1}(\Omega)$ & 0.68 & 22.93 & $-36.7 \%$ \\
Iron core losses & $\Delta P_{F e}(\mathrm{~W})$ & 64.10 & 17.18 & $-64.2 \%$ \\
Mechanical losses & $\Delta P_{m e c h}(\mathrm{~W})$ & 17.18 & 7.50 & $\mathrm{No}$ \\
Additional losses & $\Delta P_{d}(\mathrm{~W})$ & 7.50 & 41.91 & $\mathrm{No}$ \\
Stator winding copper losses & $\Delta P_{j 1}(\mathrm{~W})$ & 73.93 & 94.37 & $-43.3 \%$ \\
Overall efficiency of AFRC & $\eta(\%)$ & 90.21 & & $+4.2 \%$ \\
\hline
\end{tabular}

Figure 5 plots the magnetic flux density in air gap $\delta_{1}$ of the AFRC unit and the cogging torque, both as a function of the outer rotor position. 

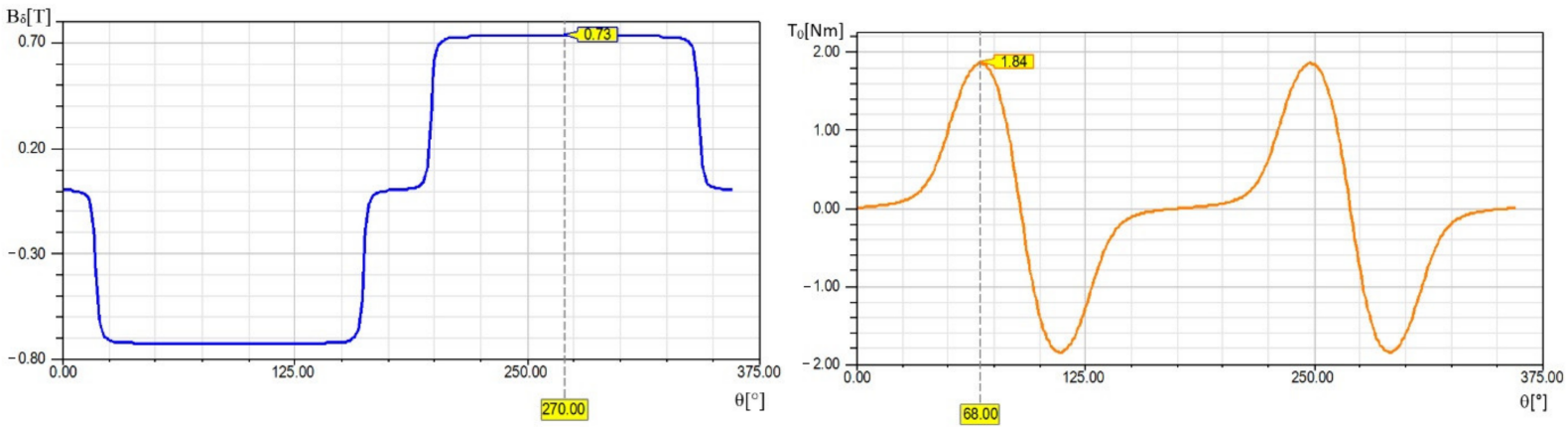

Figure 5. The magnetic flux density in air gap $\delta_{1}$ as a function of the rotor position. The blue cursor indicates the amplitude $B_{\delta}=0.73 \mathrm{~T}$ (left); cogging torque as a function of the rotor position. The yellow cursor indicates the amplitude $T_{0}=1.84 \mathrm{Nm}$ (right).

\section{D FEM Analysis of the Magnetic Conditions in the Optimized AFRC Unit}

For each component of the optimized AFRC machine, the visualization of the magnetic properties was performed by an FEM analysis in Maxwell. Figures 6-11 show the geometry of the stator and rotor packages with optimized slot shapes, containing winding, squirrel cages, and permanent magnets. Advanced meshing with local refinements in important parts was performed and the magnetic flux density distribution was visualized for each model.
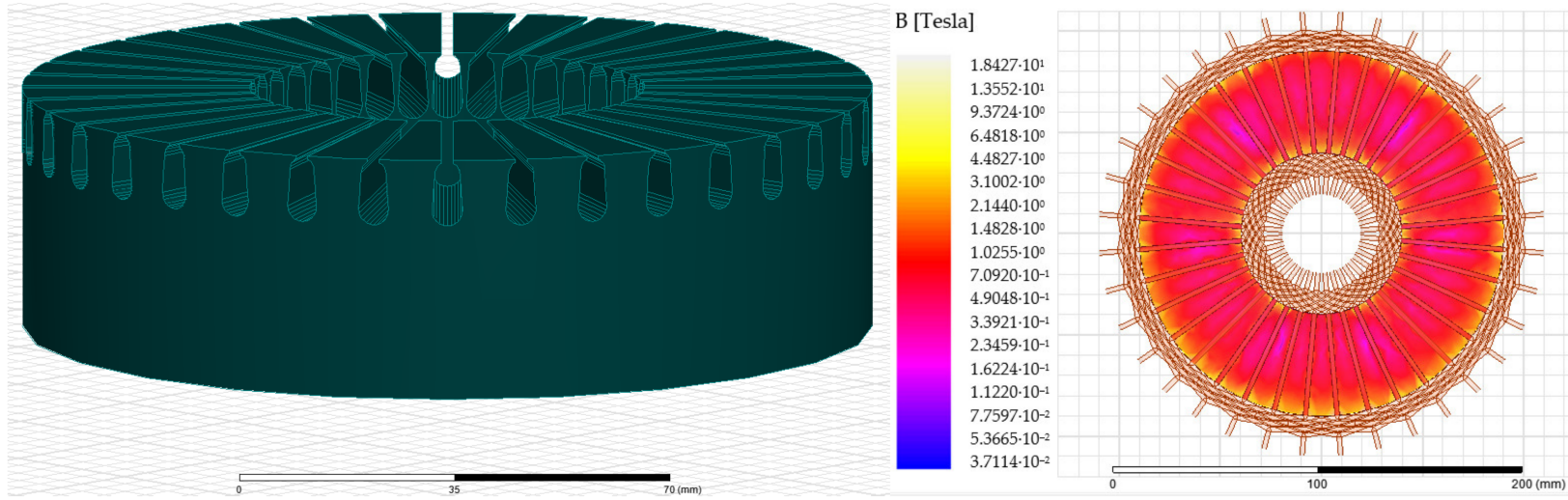

Figure 6. The 3D geometry of a stator package with an optimized slot shape (left); the distribution of the magnetic flux density in the stator, where slots are filled with a six-pole winding supplied by a nominal current (right).
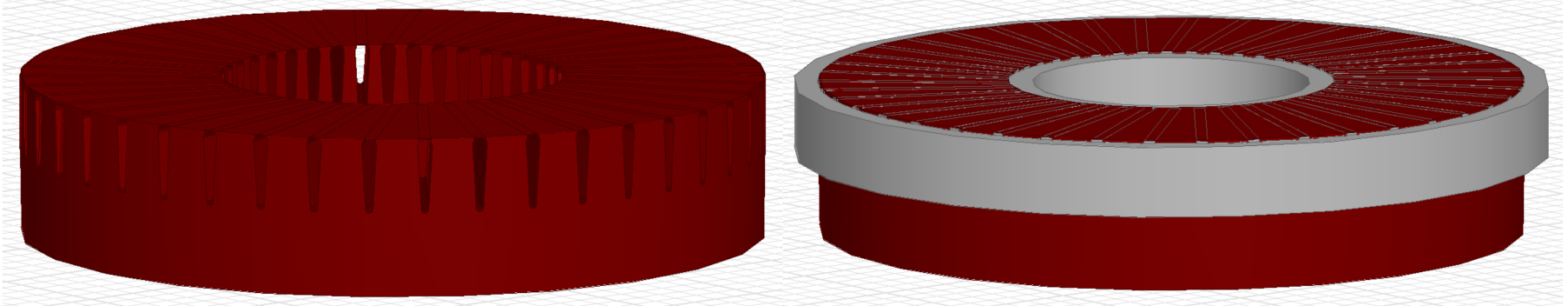

Figure 7. The 3D geometry of the symmetrical half of an inner rotor package with optimized, tilted, and closed slots (left); the same model after inserting the squirrel cage (right). 

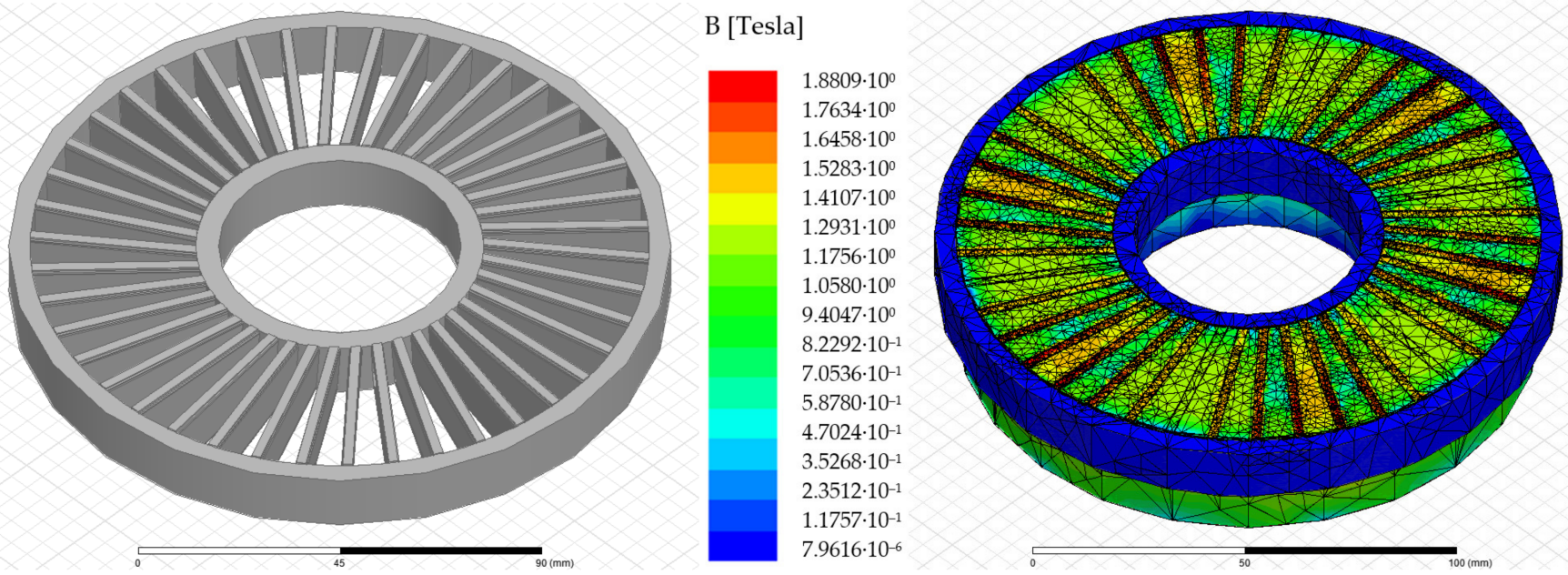

Figure 8. The 3D geometry of a squirrel cage with tilted bars (left); the distribution of the magnetic flux density in the symmetrical half of the inner rotor, visualized with advanced meshing with local refinements in the area of the rotor slots and squirrel cage bars (right).
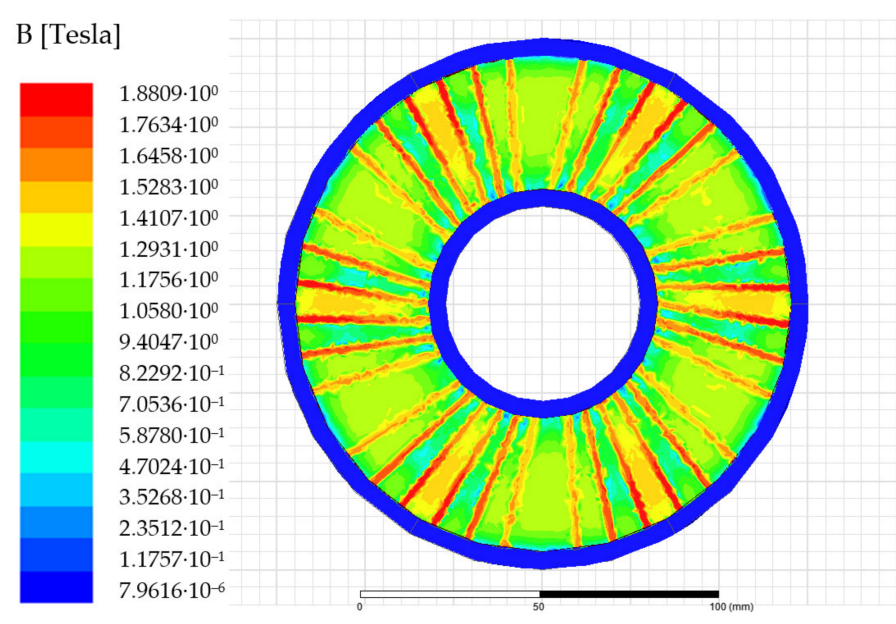

B [Tesla]
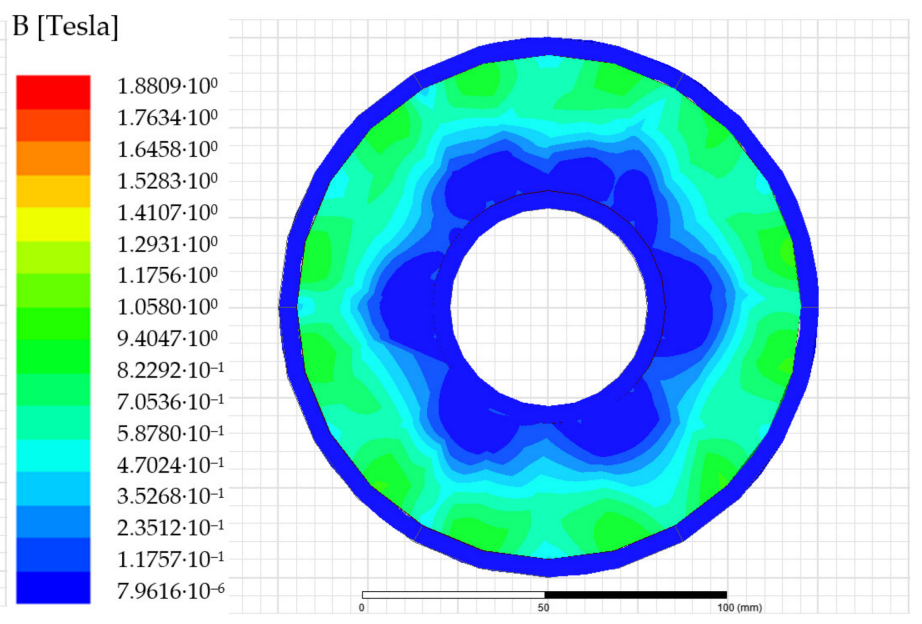

Figure 9. The distribution of the magnetic flux density in the symmetrical half of the inner rotor from the side of air gap $\delta_{2}$ (left); the distribution of the magnetic flux density in the plane of the inner rotor symmetry (right).

The situation depicted in Figure 11 occurs when the AFRC unit operates in either a purely electrical or mechanical mode when the vehicle is powered only by the battery or the ICE. The left half of the inner rotor faces the active (powered) part of the drive (in this case, the ICE), while the right half of the inner rotor faces the passive part of the drive (in this instance, it is the stator, which is not powered). 

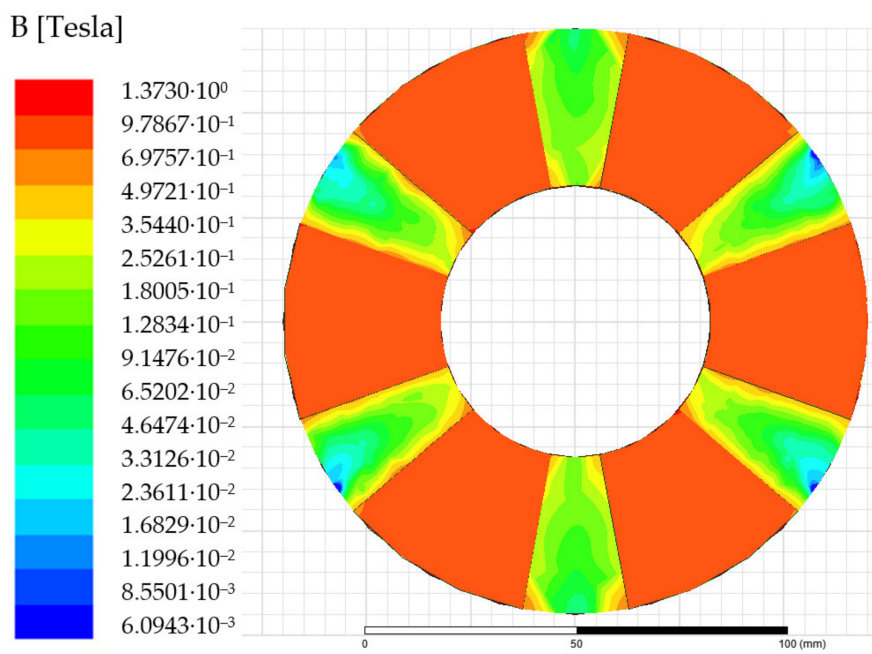

B [Tesla]
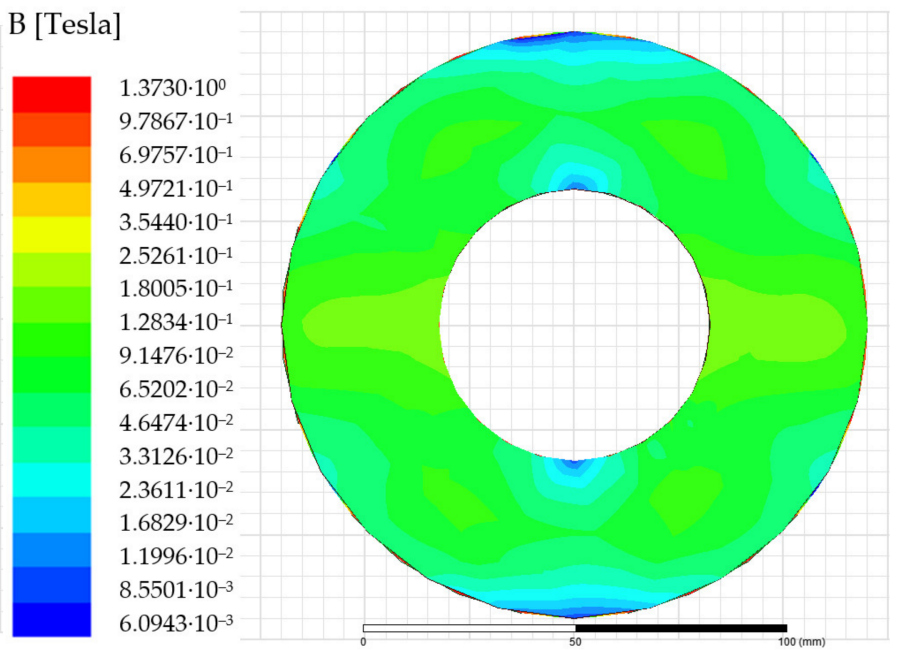

Figure 10. The distribution of the magnetic flux density in the outer rotor with permanent magnets from the side of air gap $\delta_{1}$ (left); the distribution of the magnetic flux density on the rear face of the outer rotor facing the ICE (right).

B [Tesla]
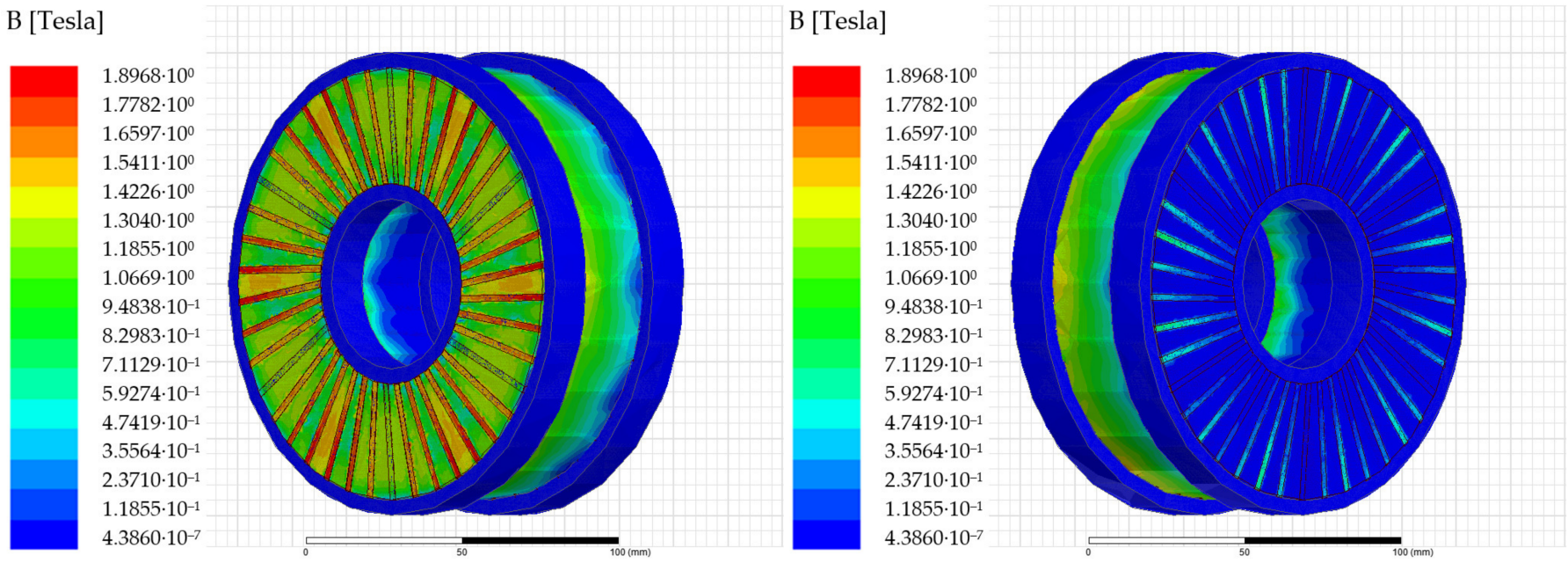

Figure 11. A nominal current flowing through the bars of the left side of the inner rotor (air gap $\delta_{1}$ ) (left); zero current flowing through the bars of the right side of the inner rotor (air gap $\delta_{2}$ ) (right).

\section{Conclusions}

This paper provides a short overview of the design, optimization, and 3D FEM analysis of an AFRC unit prototype of nominal output power $P_{2}=1500 \mathrm{~W}$. It is a novel design, characterized by a high power density. Therefore, the unit may be of use in future hybrid electric vehicles. The unit is highly efficient, combining the advantages of known series and parallel hybrid topologies while eliminating the problems and disadvantages accompanying existing solutions for four-quadrant rotary converters.

Models of AFRC unit components and 3D geometries were designed, analyzed, and optimized in the RMxprt/Maxwell environment, which allowed parallel monitoring of a large number of internal variables in the unit. This assisted our analysis of their dependencies and helped to increase the overall theoretical efficiency of the unit from $90.2 \%$ to $94.4 \%$.

Future research will focus on manufacturing a laboratory prototype, through which the results of this study can be verified in real operating conditions. Two series-produced axial flux induction motors are planned to be utilized in the laboratory implementation, 
where one of the stators will be modified into the outer rotor. The winding will be removed, stator slots milled, and permanent magnets glued in their place.

Author Contributions: All authors contributed equally to the concept of the paper, and proposed the methodology; formal analyses, and validation, A.H.; software, A.H.; investigation, M.S. and L.S.; data curation, M.S.; writing — original draft preparation, A.H.; writing—review and editing, A.H.; visualization, J.S.; supervision, project administration, and funding acquisition, A.H. All authors have read and agreed to the published version of the manuscript.

Funding: This research was funded by the Student Grant Competition of VSB-Technical University of Ostrava, grant number SP2022/48.

Institutional Review Board Statement: Not applicable.

Informed Consent Statement: Not applicable.

Data Availability Statement: Not applicable.

Conflicts of Interest: The authors declare no conflict of interest.

\section{References}

1. Boyd, S.J. Hybrid electric vehicle control strategy based on power loss calculations. Ph.D. Thesis, Virginia Polytechnic Institute and State University, Blacksburg, VA, USA, 2006.

2. Cheng, Y.; Cui, S.; Song, L.; Chan, C.C. The Study of the Operation Modes and Control Strategies of an Advanced Electromechanical Converter for Automobiles. IEEE Trans. Magn. 2007, 43, 430-433. [CrossRef]

3. Zheng, P.; Liu, R.; Thelin, P.; Nordlund, E.; Sadarangani, C. Research on the Parameters and Performances of a 4QT Prototype Machine Used for HEV. IEEE Trans. Magn. 2007, 43, 443-446. [CrossRef]

4. Zheng, P.; Liu, R.; Thelin, P.; Nordlund, E.; Sadarangani, C. Research on the Cooling System of a 4QT Prototype Machine Used for HEV. IEEE Trans. Energy Convers. 2008, 23, 61-67. [CrossRef]

5. Sadarangani, C. Hybrid Drive Device. U.S. Patent No. 7325637 B2, 5 February 2008.

6. Nordlund, E. The Four-Quadrant Transducer System for Hybrid Electric Vehicles. Ph.D. Thesis, Royal Institute of Technology, Stockholm, Sweden, 2005.

7. Lisowski, L. Continuously variable electromagnetic transmission. U.S. Patent No. 6762523, 2004.

8. Grasso, E.; Palmieri, M.; Corti, F.; Nienhaus, M.; Cupertino, F.; Grasso, F. Detection of stator turns short-circuit during sensorless operation by means of the Direct Flux Control technique. In Proceedings of the 2020 AEIT International Annual Conference (AEIT), Catania, Italy, 23-25 September 2020; pp. 1-6.

9. Smith, A.C. Harmonic field analysis for slip-ring motors including general rotor asymmetry. IEEE Trans. Ind. Appl. 1990, 26, 857-865. [CrossRef]

10. Havel, A.; Vaculik, P.; Slivka, D. Efficient Propulsion Structure with an Axial Flux Rotary Converter for HEV Drive Unit. Adv. Electr. Electron. Eng. 2011, 9, 136-142. [CrossRef]

11. Corti, F.; Gulino, M.-S.; Laschi, M.; Lozito, G.M.; Pugi, L.; Reatti, A.; Vangi, D. Time-domain circuit modelling for hybrid supercapacitors. Energies 2021, 14, 6837. [CrossRef]

12. Raman, S.R.; Cheng, K.-W.; Xue, X.-D.; Fong, Y.-C.; Cheung, S. Hybrid Energy Storage System with Vehicle Body Integrated Super-Capacitor and Li-Ion Battery: Model, Design and Implementation, for Distributed Energy Storage. Energies 2021, 14, 6553. [CrossRef]

13. Fedor, P.; Perdukova, D.; Bober, P.; Fedor, M. New Stable Non-Vector Control Structure for Induction Motor Drive. Appl. Sci. 2021, 11, 6518. [CrossRef]

14. Vo, H.H.; Kuchar, M.; Brandstetter, P. Application of fuzzy logic in sensorless induction motor drive with PWM-DTC. Electrical Eng. 2020, 102, 129-140. [CrossRef]

15. Nguyen, T.D.; Foo, G.; Tseng, K.; Vilathgamuwa, D.M. Modeling and Sensorless Direct Torque and Flux Control of a Dual-Airgap Axial Flux Permanent-Magnet Machine with Field-Weakening Operation. IEEE-ASME Trans. Mech. 2014, 19, 412-422. [CrossRef]

16. Vansompel, H.; Sergeant, P.; Dupré, L.; Van den Bossche, A. Axial-Flux PM Machines with Variable Air Gap. IEEE Trans. Ind. Electron. 2014, 61, 730-737. [CrossRef]

17. Modarres, M.; Vahedi, A.; Ghazanchaei, M. Effect of Air gap variation on characteristics of an Axial flux hysteresis motor. In Proceedings of the 2010 1st Power Electronic \& Drive Systems \& Technologies Conference (PEDSTC), Iran, Tehran, 17 February 2010.

18. Valtonen, M.; Parviainen, A.; Pyrhonen, J. Influence of the air-gap length to the performance of an axial-flux induction motor. In Proceedings of the 2008 18th International Conference on Electrical Machines, Vilamoura, Portugal, 6-9 September 2008.

19. Yildiriz, E.; Gulec, M.; Aydin, M. An Innovative Dual-Rotor Axial-Gap Flux-Switching Permanent-Magnet Machine Topology with Hybrid Excitation. IEEE Trans. Magn. 2018, 54, 1-5. [CrossRef]

20. Qiu, H.; Yu, W.; Tang, B.; Mu, Y.; Li, W.; Yang, C. Study on the Influence of Different Rotor Structures on the Axial-Radial Flux Type Synchronous Machine. IEEE Trans. Ind. Electron. 2018, 65, 5406-5413. [CrossRef] 
21. Aydin, M.; Gulec, M. A New Coreless Axial Flux Interior Permanent Magnet Synchronous Motor with Sinusoidal Rotor Segments. IEEE Trans. Magn. 2016, 52, 1-4. [CrossRef]

22. Gieras, J.F.; Wang, R.-J.; Kamper, M.J. Axial Flux Permanent Magnet Brushless Machines, 2nd ed.; Springer: Dordrecht, The Netherlands, 2008.

23. Wu, P.; Tseng, K.J. Finite element analysis of axial-gap induction motors. In Proceedings of the 4th International Power Electronics and Motion Control Conference IPEMC 2004, Xi'an, China, 14-16 August 2004.

24. Guo, B.; Huang, Y.; Peng, F.; Guo, Y.; Zhu, J. Analytical modeling of manufacturing imperfections in double-rotor axial flux PM machines: Effects on back EMF. IEEE Trans. Magn. 2017, 53, 1-5. [CrossRef] 